\section{Transconjunctival sutureless vitrectomy: initial experience and surgical tips}

P O' Reilly and S Beatty

\section{Department of}

Ophthalmology, Waterford

Regional Hospital, Waterford, Republic of Ireland

Correspondence: P O' Reilly, Department of

Ophthalmology,

Waterford Regional

Hospital,

Dunmore Road, Waterford, Republic of Ireland

Tel: + 353862863566 ;

Fax: + 35351848000 .

E-mail: mrphiliporeilly@

eircom.net

Received: 5 July 2005

Accepted in revised form:

8 December 2005

Published online: 27 January 2006

\begin{abstract}
Objectives We report the operative details and surgical outcomes of 39 consecutive transconjunctival sutureless vitrectomies using the TSV $25^{\mathrm{TM}}$ system.

Methods We retrospectively reviewed the medical records of 35 patients ( 39 eyes) who underwent surgery using TSV $25^{\mathrm{TM}}$ at the Department of Ophthalmology, Waterford Regional Hospital between March 2003 and February 2005. Preoperative, intraoperative and postoperative details were recorded and analysed. We also performed a systematic review of our surgical technique.

Results Mean ( \pm SD; range) duration of surgery was $32.85(17.54 ; 5-85) \mathrm{min}$. Methods of anaesthesia included retrobulbar anaesthesia $(31 ; 79.5 \%)$ and general anaesthesia $(8 ; 20.5 \%)$. The mean ( $\pm S D$; range) length of stay was 1.53 (1.25; 0-4) days. Mean ( \pm SD; range) visual acuities $(\log M A R)$ were $-1.335(1.15 ; 0.0$ to $-3.0)$ and $-0.803(1.03 ; 0.1$ to -3.0$)$ preoperatively and postoperatively, respectively. The mean $( \pm S D)$ intraocular pressures were 14.69 (4.64) $\mathrm{mmHg}$ and 11.56 (9.03) $\mathrm{mmHg}$ preoperatively and at the first dressing, respectively. Intraoperative complications included blockage of the $\mathrm{TSV}^{\mathrm{TM}}$ cutter tip during attempted clearance of organized intragel haemorrhage, thus requiring conversion to conventional trans pars plana vitrectomy $(1 ; 2.6 \%)$. No other intraoperative complication arose. Complications in the postoperative period included: reactivation of dormant chorioretinal toxoplasmosis $(1 ; 2.6 \%)$; postoperative posterior segment haemorrhage (3; 7.7\%); hyphaema (1; 2.6\%); transient postoperative hypotony $(10 ; 25.6 \%)$. Conclusions With appropriate case selection, and with appreciation of this technique's
\end{abstract}

limitations, transconjunctival sutureless vitrectomy is a safe procedure.

Eye (2007) 21, 518-521. doi:10.1038/sj.eye.6702255; published online 27 January 2006

Keywords: transconjunctival; sutureless; vitrectomy; tsv; technique; outcome

Introduction

The use of 25 gauge transconjunctival sutureless vitrectomy (TSV $25^{\mathrm{TM}}$ ) has many advantages over conventional trans pars plana vitrectomy. First, the self-sealing transconjunctival sclerotomies obviate the need for conjunctival peritomy, with a consequential reduction of operating time and surgically induced trauma at the sclerotomy sites. Discomfort from conjunctival sutures is also eliminated using the TSV 25 system, as is postoperative astigmatism arising from scleral sutures. A less cited, but very important, advantage of the TSV 25 system rests on the absence of subconjunctival fibrosis and adhesions postoperatively, thus rendering any subsequent vitreoretinal and/or filtration surgery easier. Finally, transconjunctival sutureless vitrectomy results in a more aesthetically pleasing eye in the immediate postoperative period. We report on the experience of the first 39 consecutive cases of vitreoretinal surgery using the TSV 25 system in our unit, and discuss the outcomes thereof and make recommendations so that other vitreoretinal surgeons can avoid pitfalls with this novel and innovative technique.

Materials and methods

We retrospectively reviewed the medical records of 35 patients (39 eyes) who consecutively underwent trans pars plana 
vitrectomy using the TSV 25 system at the Department of Ophthalmology at Waterford Regional Hospital between March 2003 and February 2005. Data retrieved may be classed as preoperative, intraoperative and postoperative. Preoperative details recorded included: intraocular pressure (IOP) and visual acuity (VA); indications for surgery; ophthalmic details, including previous intraocular surgery in the study eyes. Intraoperative data included: method of anaesthesia; operating time; complications (if any). Postoperative details included IOP and VA recordings, as well as the clinical course. VA was typically recorded in the medical records as Snellen visual acuity, but this was converted to the $\log$ MAR scale using a conversion chart ${ }^{1}$ to aid with statistical analysis.

\section{Surgical technique}

A Bausch and Lomb Millennium ${ }^{\mathrm{TM}}$ TSV $25^{\mathrm{TM}}$ System for transconjunctival standard vitrectomy was used in all cases. We created three ports through the pars plana, in the superotemporal, superonasal, and inferotemporal quadrants, respectively. No conjunctival peritomy was performed and an entry site alignment system was used to maintain alignment between the conjunctival and scleral entry sites. Microcannulae were used to facilitate this, which consist of thin-walled polyamide tubes $3.6 \mathrm{~mm}$ in length with an inner/outer diameter of $0.57 / 0.62 \mathrm{~mm}$ and were inserted into the eye using a trocar. We displaced the conjunctiva laterally when inserting the microcannulae and sutures were not required to hold these in place. The first microcannula was inserted inferotemporally to provide access for the infusion cannula (which does not need to be sutured in place). We placed the other microcannulae more inferiorly than typical, at 10 and $2 \mathrm{O}^{\prime}$ clock instead of at the conventional 11 and $1 \mathrm{O}^{\prime}$ clock positions, thus allowing a better view of superior vitreous and retina intraoperatively. The surgeries were performed using 25 gauge instrumentation, introduced into the eyes via the preplaced microcannulae. Postoperatively the microcannulae were removed and the conjunctiva gently manipulated over the sclerotomy sites to prevent leakage.

\section{Results}

Mean ( \pm standard deviation (SD)) age of patients at the time of surgery was 67.63 (13.31) years and the male to female ratio was $22: 17$. Indications for surgery are given in Table 1. In all, 31 (79.5\%) surgeries were performed using retrobulbar anaesthesia, and the remaining eight (20.5\%) were performed under general anaesthesia. The mean duration $( \pm S D$ ) of surgery was 32.85 (17.54) $\mathrm{min}$,
Table 1 Indications for surgery of 39 consecutive cases of vitreoretinal surgery using transconjunctival sutureless vitrectomy (TSV 25) at Waterford Regional Hospital from March 2003 to February 2005

\begin{tabular}{lcc}
\hline Indication for surgery & $\begin{array}{c}\text { No. of } \\
\text { patients }\end{array}$ & $\begin{array}{c}\text { Percentage of } \\
\text { patients (\%) }\end{array}$ \\
\hline $\begin{array}{l}\text { Vitreous floaters/opacities } \\
\text { Vitreous haemorrhage }\end{array}$ & 14 & 35.90 \\
$\begin{array}{l}\text { Epiretinal membrane peel } \\
\text { Retained lens fragments after }\end{array}$ & 6 & 25.60 \\
complicated cataract surgery & 5 & 15.40 \\
$\begin{array}{l}\text { Asteroid hyalosis } \\
\text { Macular hole }\end{array}$ & 2 & 12.80 \\
$\begin{array}{l}\text { Induction of posterior vitreous } \\
\text { detachment (central retinal vein }\end{array}$ & 1 & 5.10 \\
occlusion) & & 2.60 \\
\hline
\end{tabular}

with a range of $5-85 \mathrm{~min}$. Seven $(17.95 \%)$ cases were performed on a daycase basis and the mean length of hospital stay was 1.53 (1.25) days with a range of $0-4$ days.

Mean ( \pm SD; range) visual acuities (logMAR) were $-1.335(1.15 ; 0.0--3.0)$ and $-0.803(1.03 ; 0.1$ to -3.0$)$ preoperatively and postoperatively, respectively. The mean $( \pm S D)$ intraocular pressures were 14.69 (4.64) and $11.56(9.03) \mathrm{mmHg}$ preoperatively and at the first dressing, respectively. In all, 10 eyes $(25.6 \%)$ suffered transient postoperative hypotony (IOP $<5 \mathrm{mmHg}$ ) for at least one postoperative day; however, by day 4 the intraocular pressure had normalized in all of these cases.

One intraoperative complication arose, where TSV ${ }^{\mathrm{TM}}$ cutter tip became blocked during attempted clearance of organized intragel haemorrhage, necessitating enlargement of the sclerotomy and conversion to conventional the trans pars plana vitrectomy. Of note, no TSV $25^{\mathrm{TM}}$ sclerotomy sites required suturing in the postoperative period due to leakage. Complications in the postoperative period included: reactivation of dormant chorioretinal toxoplasmosis $(1 ; 2.6 \%)$; postoperative posterior segment haemorrhage $(3 ; 7.7 \%)$; hyphaema $(1 ; 2.6 \%)$; transient postoperative hypotony $(10 ; 25.6 \%)$.

\section{Discussion}

Transconjunctival sutureless vitrectomy was first described by Fujii et $a l^{2,3}$ in 2002. Since then there have been a paucity of articles describing and exploring the potential indications for this technique, as well as surgical complications. ${ }^{1-8}$ We report the first 39 consecutive transconjunctival vitrectomies performed at Waterford Regional Hospital, discuss our experience 
with this relatively new technique, and furnish the reader with some surgical pointers to avoid potential complications with this technology.

In our series, we encountered no complication with the TSV $25^{\mathrm{TM}}$ system, which can be attributed to the use of this method over conventional trans pars plana vitrectomy, other than a transient hypotony. We defined postoperative hypotony as an intraocular pressure of less than or equal to $5 \mathrm{mmHg}$ on the first postoperative day. The prevalence of this complication was high (10/39; $25.6 \%$ ) presumably due to the sutureless nature of this technique and consequent slow leakage from the entry ports. Risks associated with transient postoperative hypotony include an increased risk of endophthalmitis (due to the facilitation of intraocular access to microorganisms) and an increased risk of choroidal detachment. None of these eyes however, suffered choroidal detachments or any adverse sequelae and intraocular pressure had normalized by day 4 postoperatively in all cases. Of note, the prevalence of postoperative posterior segment haemorrhage following TSV $25^{\mathrm{TM}}$ vitrectomy for haemorrhage clearance, was also high $(3 / 10 ; 30 \%)$ and may be related to the postoperative hypotony. To try and reduce the incidence of postoperative hypotony, we recommend that the surgeon displace the conjunctiva laterally when inserting the microcannulae so that the anatomical recoil of the displaced conjunctiva will ensure that the sclerotomies are adequately covered in the immediate postoperative period, thus reducing the risk of leakage and/or infection (see Table 2). In any case, no complications resulted in long-term sequelae, which compromised the vision.

As with all new and innovative techniques, there are potential advantages and disadvantages to consider. Advantages of transconjunctival sutureless vitrectomy include a reduction in operating time, thus enhancing theatre efficiency. Another advantage of the TSV $25^{\mathrm{TM}}$ system includes less subconjunctival adhesion formation postoperatively, thus facilitating any subsequent vitreoretinal surgery or filtration surgery, if required. Further, the introduction of instruments through a microcannula should, in theory, be associated with a lower risk of entry site breaks, because shearing of the vitreous base upon repeated introduction of surgical instruments through a conventional sclerotomy is avoided. Finally, transconjunctival sutureless vitrectomy is associated with a more aesthetically pleasing appearance of the eye in the immediate postoperative period when compared with the appearance following traditional pars plana vitrectomy.

The disadvantages of TSV $25^{\mathrm{TM}}$ vitrectomy include an increased incidence of postoperative hypotony, thus necessitating daily review of the patient and possibly affecting the proportion of patients suitable for daycase surgery. Also, the instruments for TSV 25 vitrectomy are very small and malleable, resulting in limited maneuverability of the eye. Further, the small size of the cutting port and a potentially weaker aspiration may lead to difficulty with clearance of dense vitreous haemorrhage and with induction of posterior vitreous detachment,

Table 2 Surgical tips for those making the transition from conventional trans pars plana vitrectomy to transconjunctival sutureless vitrectomy

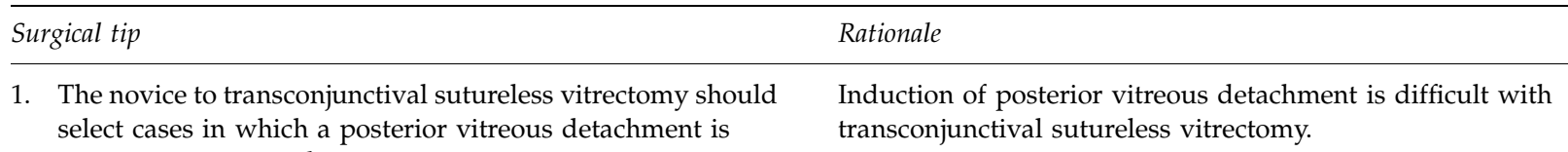
present preoperatively.

2. When setting up for phacovitrectomy using transconjunctival sutureless vitrectomy, place the microcannulae before cataract surgery. Following cataract surgery, proceed with trans pars plana vitrectomy using the preplaced microcannulae.

3. Displace the conjunctiva laterally when inserting the microcannulae.

4. Place the microcannulae more inferiorly; we recommend placement of the microcannulae at 10 and $2 \mathrm{O}^{\prime}$ clock, rather than at 11 and $1 \mathrm{O}^{\prime}$ clock.

5. Have an experienced assistant to rotate the eye as required, during the surgery (using a St Martins forceps).

6. When withdrawing instruments intra-operatively (eg swapping hands or putting in new instruments), a forceps should be used by the assistant to stabilize the collar of the microcannula.

This will avoid introducing the microcannulae into a soft eye, thus potentially displacing the intraocular lens.

The anatomical recoil of the displaced conjunctiva will ensure that the sclerotomies are adequately covered in the immediate post-operative period, thus reducing the risk of leakage and/or infection.

This compensates for the limited maneuverability of the eye and facilitates enhanced visualization of the superior vitreous and retina.

This will facilitate the surgeon to see the peripheral vitreous and retina.

Occasionally microcannulae may become dislodged upon withdrawal of instruments; in these circumstances, it may prove impossible to reinsert the microcannula into a soft eye. 
respectively. Moreover, there is a theoretically increased risk of endophthalmitis following transconjunctival sutureless vitrectomy because of the transient hypotony with consequential facilitation of intraocular access to microorganisms. And finally, there is an inevitable learning curve inherent with any new surgical technique, which will represent additional psychological stress to the surgeon and surgical assistants.

We have compiled a list of surgical pointers to aid those contemplating transconjunctival sutureless vitrectomy, so that potential pitfalls can be avoided (Table 2).

In summary, we believe that the TSV $25^{\mathrm{TM}}$ vitrectomy system, or similar transconjunctival vitrectomy methods, represent a significant advance in vitreoretinal surgery, and has a role to play. TSV $25^{\mathrm{TM}}$ vitrectomy is a safe and effective procedure for a wide variety of vitreoretinal indications and we believe that vitreoretinal surgeons should become acquainted with this new technology, and comfortable with it, at the very least for simple internal posterior segment procedures or surgeries. In the context of appropriate case selection, and with full appreciation of the limitations of transconjunctival sutureless vitrectomy, transconjunctival sutureless vitrectomy does not compromise the surgical or visual outcome of internal posterior segment surgery.

\section{References}

1 Holladay JT. Guest Editorial. Visual acuity measurements. J Cat Refract Surg 2004; 30(2): 287-290.

2 Fujii GY, de Juan Jr E, Humayun MS, Pieramici DJ, Chang TS, Awh C et al. A new 25-guage instrument system for transconjunctival sutureless vitrectomy surgery. Ophthalmology 2002; 109: 1807-1813.

3 Fujii GY, de Juan Jr E, Humayun MS, Chang TS, Pieramici DJ, Barnes A et al. Initial experience using the transconjunctival sutureless vitrectomy system for vitreoretinal surgery. Ophthalmology 2002; 109: 1814-1820.

4 Ibarra MS, Hermel M, Prenner JL, Hassan TS. Longer-term outcomes of transconjunctival sutureless 25-gauge vitrectomy. Am J Ophthalmol 2005; 139(5): 831-836.

5 Hilton GF, Josephberg RG, Halperin LS, Madreperla SA, Brinton DA, Lee SS et al. Office-based sutureless transconjunctival pars plana vitrectomy. Retina 2002; 22(6): 725-732.

6 Eckardt C. Transconjunctival sutureless 23-gauge vitrectomy. Retina 2005; 25(2): 208-211.

7 Lee HK, Kim CY, Kwon OW, Kim EK, Lee SC, Seong GJ et al. Removal of dense posterior capsule opacification after congenital cataract extraction using the transconjunctival sutureless vitrectomy system. J Cataract Refract Surg 2004; 30(8): 1626-1628.

8 Shah VA, Gupta SK, Chalam KV. Management of vitreous loss during cataract surgery under topical anaesthesia with transconjunctival vitrectomy system. Eur J Ophthalmol 2003; 13(8): 693-696. 